ORIGINAL ARTICLE

\title{
Can the Griffiths scales predict neuromotor and perceptual- motor impairment in term infants with neonatal encephalopathy?
}

\author{
A L Barnett, A Guzzetta, E Mercuri, S E Henderson, L Haataja, F Cowan, L Dubowitz
}

Arch Dis Child 2004;89:637-643. doi: 10.1136/adc.2002.019349

See end of article for authors' affiliations

Correspondence to: Dr E Mercuri, Department of Paediatrics, Hammersmith Hospital, Du Cane Road, London W12 OHN, UK; e.mercuri@ ic.ac.uk

Accepted 6 April 2003

\begin{abstract}
Aims: To examine the predictive value of early developmental testing for identifying neuromotor and perceptual-motor impairment at school age in children with neonatal encephalopathy (NE).

Methods: Eighty full term infants with NE were followed longitudinally. Where possible, children were tested on the Griffiths scales at 1 and 2 years and at 5-6 years, on the Touwen Examination, Movement $A B C$, and WPPSI. The relation between the Griffiths scores and later outcome measures was examined using correlation coefficients and sensitivity and specificity values.

Results: By 2 years, 25 children with cerebral palsy were too severely impaired to be formally assessed and remained so at $5-6$ years. Abnormal Griffiths scores were obtained by $12 \%$ and $7 \%$ of the children at 1 and 2 years respectively. At 5-6 years, 33\% had poor Movement ABC scores and 15\% poor WPPSI scores. The highest correlation between Griffiths scores and the outcome measures was for the Movement $A B C(0.72)$, although this accounted for only $50 \%$ of the variance. Sensitivity scores for the Movement $A B C$ were below $70 \%$ but specificity was $100 \%$.

Conclusions: A poor score on the Griffiths scales at 1 and/or 2 years is a good predictor of impairment at school age. However, a normal score in the early years cannot preclude later neurological, perceptualmotor, or cognitive abnormalities.
\end{abstract}

$\mathrm{D}$ evelopmental tests have been used since the $1930 \mathrm{~s}^{1-5}$ and continue to be recognised as valuable tools for assessing the development of infants and young children. ${ }^{6}$ Such tests have been employed with various "at risk" groups, to identify and describe current problems and to predict later developmental status. For many years now, however, their predictive value has been seriously questioned. ${ }^{6-8}$

Longitudinal studies which have examined the relation between performance on infant developmental tests, such as the Griffiths and Bayley scales and later outcome have mainly concentrated on cognitive outcome. ${ }^{9-13}$ In non-risk populations, such studies report only modest correlations, especially from any assessment made prior to the age of 2 years. ${ }^{14}{ }^{15}$ In contrast, studies of cohorts likely to contain severely impaired children, such as very preterm infants, report better prediction of future test performance even when the tests were performed under the age of 2 years. ${ }^{76-18}$ However, this may be due to the fact that correlations between early and later assessments are sometimes inflated by scores assigned to very impaired children who may be almost untestable. Whereas the predictive value of development tests for cognitive development has received a great deal of attention, the power of the same tests for predicting perceptual-motor outcome remains relatively unexplored. This is surprising given the number of recent studies documenting the serious educational, psychological, and social effects of such impairment. ${ }^{19-24}$

One group considered to be "at risk" for later neurodevelopmental problems are infants presenting with neonatal encephalopathy (NE). This group includes infants who in the past were labelled as having hypoxic ischaemic encephalopathy as well as those presenting with neonatal convulsions. In all clinical settings, such children are followed up for a short period of time in order to chart progress and identify problems. In many cases, those with normal results on neurodevelopmental tests at 1 year or 18 months would then be discharged. By following up these children until school age, however, we have recently found that a proportion, while not developing cerebral palsy, still present with minor neurological and/or perceptual-motor problems. ${ }^{25}$

The primary aim of the present study was to examine the predictive value of developmental testing performed at 1 and 2 years of age for identifying perceptual-motor impairment at school age in children born at term with NE. In order that we could compare our results with those of other studies focusing on this particular group of children, cognitive development was also assessed. The instrument used in the early years was the Griffiths Scales of Mental Development. ${ }^{26}$ Since this test yields standardised scores on a series of five subsections as well as a total score, we took the opportunity to examine the relation between these and later performance as well as for the test as a whole. At school age, children were assessed on the Movement ABC and the WPPSI. A particular strength of the study was that the school age assessments were carried out by an assessor blind to the results of all earlier testing.

\section{METHODS}

\section{Participants}

Ethical permission for this study was obtained from the Hammersmith Hospital Research Ethics Committee. The children described in this paper are part of a large prospective cohort of term infants born at or referred to the Hammersmith Hospital, London. The diagnosis of neonatal encephalopathy was made in infants who had convulsions and/or showed other abnormal neurological signs during the first 48 hours after delivery. Neurological abnormalities included abnormal tone, poor feeding, and altered level of consciousness. Infants who subsequently had been diagnosed as suffering from genetic or metabolic syndromes or who presented with other neonatal complications, such as 
septicaemia or neonatal meningitis, were excluded from the study. In addition, infants with dysmorphic features or other clinical or brain magnetic resonance imaging findings suggesting major congenital malformation were excluded.

Infants were included in the study if they met the following criteria: (1) attended a follow up assessment at 1 and/or 2 years of age ( \pm 3 months); and (2) attended a further assessment between the age of 5 years 6 months and 6 years 6 months.

\section{Developmental assessment at 1 and 2 years}

We used the Griffiths Mental Development Scales ${ }^{26}$ for children aged 0-2 years. This contains five separate scales: locomotor, personal-social, hearing and speech, eye and hand coordination, and performance. The total developmental quotient (DQ) and sub-quotients were calculated as described in the manual. The DQ has a mean of 100 and a standard deviation of 13. All children were assessed by paediatricians experienced in neurodevelopmental examination and who had completed an accredited training course on the Griffiths scales. For the purposes of this study, we defined a "normal" DQ as $\geqslant 87$.

\section{Follow up assessment at 5-6 years}

The children were reassessed between the age of $51 / 2$ and $6 \frac{1}{2}$ years. Their neurological status, motor competence, and cognitive ability were assessed as described below.

\section{Neurological examination}

A structured neurological examination was performed using a modified form of Touwen's Examination of the Child with Minor Neurological Dysfunction..$^{28}$ This was used to identify the type and extent of motor impairment or any other neurological dysfunction. Cerebral palsy, when present, was classified according to the criteria described by Hagberg. ${ }^{29}$

\section{Motor competence}

The Movement Assessment Battery for Children (Movement $\mathrm{ABC})^{30}$ was administered by a psychologist unaware of the results of the earlier assessments from the Griffiths scales and was used to assess the children's performance on a range of functional tasks. The three manual dexterity items, two ball skill items, and three balance items from Age Band One of the test were administered. Total scores were obtained and expressed as centiles based on information from the test manual. Scores between the 5 th and 15 th centile points were considered borderline, while those falling at or below the 5th centile were considered to be indicative of a definite motor problem. Reliability and validity information is presented both in the test manual and more recently by Croce and colleagues. ${ }^{31}$

\section{Cognitive ability}

The Wechsler Pre-school and Primary Scale of IntelligenceRevised (WPPSI) ${ }^{32}$ was administered by the same psychologist and used to obtain separate measures of verbal and performance IQ as well as a full scale intelligent quotient. The five "verbal" and five "performance" items were administered and scored according to the manual. The quotients have a mean of 100 and a standard deviation of 15. In this study, we defined a "normal" IQ as equal to or greater than 85 .

\section{Analyses}

A range of statistical and descriptive analyses were carried out. Pearson correlation coefficients were calculated to estimate the relation between the early Griffiths scores and the Movement ABC and WPPSI scores at school age. Secondly, sensitivity and specificity values were calculated for the Griffiths scores and perceptual-motor and cognitive outcome. Positive predictive values and negative predictive values were also calculated. Finally, we examined the Griffiths scores and school age data for each child individually.

\section{RESULTS}

Of the 123 children with neonatal encephalopathy born at or referred to our hospital between May 1991 and September 1996, 16 died in the neonatal period or in early infancy. Ten were excluded from the study because of congenital malformation or genetic, viral, or metabolic syndromes. Ninety seven children were enrolled for follow up. In 15 of these, the age of evaluation did not meet our criteria. Two other children were lost to follow up. The outcome of the remaining 80 children is reported in this study.

\section{Griffiths Mental Development Scales}

Twenty of the 80 children were too severely affected to be formally assessed at either 1 or 2 years of age. Of the remaining 60, 59 children were available for assessment at 1 year. At 2 years 45 children completed the assessment. Five of the 15 not included at 2 years had become untestable because of the severity of their impairments. The remaining 10 had been assessed between 1 and 3 years but did not meet our criterion of being assessed within three months of their second birthday.

Table 1 shows the results for the sub-quotients and total development quotients for the 59 and 45 children tested at 1 and 2 years respectively. At both ages the range of scores was wide on all components, extending from a low of 35 on the locomotor scale to a high of 158 on the performance scale.

Table 1 Summary results on the Griffiths scales at 1 and 2 years

\begin{tabular}{|c|c|c|c|c|c|c|}
\hline & Locomotor & $\begin{array}{l}\text { Personal/ } \\
\text { social }\end{array}$ & $\begin{array}{l}\text { Hearing and } \\
\text { speech }\end{array}$ & $\begin{array}{l}\text { Eye and } \\
\text { hand }\end{array}$ & Performance & DQ \\
\hline \multicolumn{7}{|l|}{1 year $(n=59)$} \\
\hline Mean & 103.32 & 102.73 & 97.70 & 98.07 & 99.98 & 100.34 \\
\hline SD & 19.45 & 14.00 & 16.37 & 16.25 & 17.23 & 15.05 \\
\hline Range & $35-133$ & $57-135$ & $47-133$ & $44-131$ & $48-141$ & $55-130$ \\
\hline $\begin{array}{l}\text { Number }(\%)<1 \text { SD } \\
\text { below mean }\end{array}$ & $7(11.9)$ & $5(8.5)$ & $11(18.6)$ & $8(13.6)$ & $6(10.3)$ & $7(11.9)$ \\
\hline \multicolumn{7}{|l|}{2 years $(n=45)$} \\
\hline Mean & 104.62 & 106.67 & 102.18 & 99.04 & 105.18 & 103.53 \\
\hline SD & 12.14 & 13.87 & 20.78 & 12.18 & 17.79 & 12.33 \\
\hline Range & $87-151$ & $80-151$ & $62-150$ & $75-133$ & $62-158$ & $81-140$ \\
\hline $\begin{array}{l}\text { Number }(\%)<1 \mathrm{SD} \\
\text { below mean }\end{array}$ & 0 & $3(6.7)$ & $10(22.2)$ & $4(8.9)$ & $4(8.9)$ & $3(6.7)$ \\
\hline
\end{tabular}


Table 2 Summary results on the follow up assessments at 5-6 years

\begin{tabular}{|c|c|c|}
\hline & $\begin{array}{l}\text { Movement ABC } \\
\text { (total score) }\end{array}$ & WPPSI Full Scale IQ \\
\hline No. assessed & 55 & 53 \\
\hline Mean & 9.18 & 101.98 \\
\hline Median & 4.50 & 101.00 \\
\hline SD & 9.97 & 16.06 \\
\hline Range & $0-40$ & $69-139$ \\
\hline $\begin{array}{l}\text { No. }(\%) \text { below set } \\
\text { criteria* }^{*}\end{array}$ & $18(32.7)$ & $8(15.1)$ \\
\hline
\end{tabular}

Seven children obtained total DQs more than 1 standard deviation below the mean at 1 year; the remaining 52 (88\%) were in the "normal" range. At 2 years, only three children "failed" the test and the percentage "passing" had risen to $93 \%$.

\section{Follow up at 5-6 years}

Neurological examination

Thirty two children in the cohort (40\%) had cerebral palsy. Twenty of these had severe spastic quadriplegia, three had mild quadriplegia or diplegia, three had athetoid cerebral palsy, five had hemiplegia, and one had ataxic cerebral palsy.

Twenty five of the children with cerebral palsy had additional sensory and cognitive impairments and were too severely affected to be fully assessed on our tests. Table 2 presents results of the follow up assessments for the remaining 55 children from our cohort.

\section{Movement $A B C$}

Thirty seven of the 55 children tested (67\%) had a total score above the 15th centile and $18(33 \%)$ had scores below. Ten of the 18 children below the 15 th centile had scores below the 5 th.

\section{WPPSI}

Two children did not complete the WPPSI due to noncooperation. Of the remaining 53, $45(85 \%)$ had a full IQ of 85 or above and eight (15\%) below.

\section{Movement $A B C$ and WPPSI}

Of the 18 children with Movement $\mathrm{ABC}$ scores below the 15th centile, nine had IQs above 85 and seven below. The remaining two had incomplete data on the WPPSI.

\section{The relation between Griffiths scores at 1 and 2 years and outcome}

Perceptual-motor and neuromotor outcome

Figures 1 and 2 show details of the relation between performance on the Griffiths and Movement ABC tests for the 80 children in the study. Of the children who had "normal" DQs on the Griffiths scales at either 1 or 2 years, over 70\% had "normal" scores on the Movement ABC (37/52 at 1 year and 32/42 at 2 years). However, this left a total of 15 children at 1 year and 10 at 2 years, who did not fall into the same category at school age.

In addition to the 20 children who were untestable at any age, six children who developed quadriplegia, diplegia, or athetoid cerebral palsy, obtained a poor score, or none at all on the Griffiths and Movement ABC because they were either completely untestable or testable on only a few of the test items. In contrast, only one of the five children with hemiplegia had an abnormal score on the Griffiths test but all had poor scores on the Movement ABC. Among the 11 children who had low scores on the Movement ABC but did not have cerebral palsy, 20\% had abnormal Griffiths scores at 1 year $(2 / 10)$ and $63 \%$ at 2 years $(5 / 8)$.

\section{Cognitive outcome}

Figures 3 and 4 show details of the relation between the Griffiths and the WPPSI for individual children. More than $80 \%$ of the children who had a normal DQ on the Griffiths scales also had normal scores on the WPPSI (43/52 at 1 year and $38 / 42$ at 2 years). All but one of the children who had low DQs on the Griffiths also had low scores on the WPPSI. Those

\begin{tabular}{|c|c|c|c|c|c|c|c|}
\hline \multirow[t]{2}{*}{ Total $=80$} & \multirow[t]{2}{*}{$\begin{array}{c}\text { Normal } A B C \\
n=37\end{array}$} & \multirow[t]{2}{*}{$\begin{array}{c}\text { Poor } A B C \\
\text { No cerebral palsy } \\
n=11\end{array}$} & \multicolumn{4}{|c|}{$\begin{array}{c}\text { Poor } A B C \\
\text { with cerebral palsy } \\
n=12\end{array}$} & \multirow{2}{*}{$\begin{array}{c}\begin{array}{c}\text { Untestable } \\
n=20\end{array} \\
\begin{array}{c}\text { Severe spastic } \\
\text { quadriplegia }\end{array}\end{array}$} \\
\hline & & & $\begin{array}{c}\text { Ataxia } \\
\mathrm{n}=1\end{array}$ & $\begin{array}{c}\text { Hemiplegia } \\
n=5\end{array}$ & $\begin{array}{c}\text { Athetoid } \\
n=3\end{array}$ & $\begin{array}{c}\text { Diplegia/mild } \\
\text { quadriplegia } n=3\end{array}$ & \\
\hline Total DQ & $\begin{array}{l}\text { O0000000000 } \\
\text { O0000000000 } \\
\text { O0000000000 } \\
\text { O000 }\end{array}$ & О00000000 - & 0 & 000000 & 000 & 000 & $\begin{array}{l}\text { UUUUUUUUU } \\
\text { UUUUUUUUU } \\
\text { UU }\end{array}$ \\
\hline $\begin{array}{l}\text { Locomotor } \\
\text { score }\end{array}$ & $\begin{array}{l}\text { O0000000000 } \\
\text { O0000000000 } \\
\text { O0000000000 } \\
\text { O०00 }\end{array}$ & O०0000000 - & $\mathrm{O}$ & 000000 & 000 & 000 & $\begin{array}{l}\text { UUUUUUUUU } \\
\text { UUUUUUUUU } \\
\text { UU }\end{array}$ \\
\hline $\begin{array}{l}\text { Eye/hand } \\
\text { score }\end{array}$ & $\begin{array}{l}\text { O०000000000 } \\
\text { O०000000000 } \\
\text { O०000000000 } \\
\text { O००• }\end{array}$ & $0000000000-$ & $\mathrm{O}$ & 000000 & 000 & 000 & $\begin{array}{l}\text { UUUUUUUUU } \\
\text { UUUUUUUUU } \\
\text { UU }\end{array}$ \\
\hline $\begin{array}{l}\text { Performance } \\
\text { score }\end{array}$ & 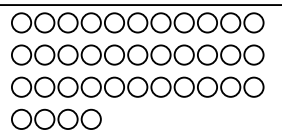 & $0000000000-$ & $\mathrm{O}$ & 000000 & 000 & 000 & $\begin{array}{l}\text { UUUUUUUUU } \\
\text { UUUUUUUUU } \\
\text { UU }\end{array}$ \\
\hline
\end{tabular}

Griffiths scores: Oscore within or above 1 SD of the mean, - score below 1 SD of the mean, U untestable, - missing data

* For two of the children with athetoid CP and the three children with diplegia/mild quadriplegia only part of the Movement $A B C$ test could be administered due to the severity of their motor impairments.

Figure 1 The relation between performance on the Griffiths at 1 year and later performance on the Movement ABC for individual children. 


\begin{tabular}{|c|c|c|c|c|c|c|c|}
\hline \multirow[t]{2}{*}{ Total $=80$} & \multirow[t]{2}{*}{$\begin{array}{c}\text { Normal } A B C \\
n=37\end{array}$} & \multirow[t]{2}{*}{$\begin{array}{c}\text { Poor } A B C \\
\text { No cerebral palsy } \\
n=11\end{array}$} & \multicolumn{4}{|c|}{$\begin{array}{c}\text { Poor } A B C \\
\text { with cerebral palsy } \\
n=12\end{array}$} & \multirow{2}{*}{$\begin{array}{c}\begin{array}{c}\text { Untestable } \\
n=20\end{array} \\
\begin{array}{c}\text { Severe spastic } \\
\text { quadriplegia }\end{array}\end{array}$} \\
\hline & & & $\begin{array}{c}\text { Ataxia } \\
\mathrm{n}=1\end{array}$ & $\begin{array}{c}\text { Hemiplegia } \\
n=5\end{array}$ & $\begin{array}{c}\text { Athetoid } \\
n=3\end{array}$ & $\begin{array}{c}\text { Diplegia/mild } \\
\text { quadriplegia } n=3\end{array}$ & \\
\hline Total DQ & $\begin{array}{l}\text { O०0000000000 } \\
000000000000 \\
00000000 \\
-----\end{array}$ & $0-000-000-0$ & - & $000-0$ & OUU & UUU & $\begin{array}{l}\text { UUUUUUUUU } \\
\text { UUUUUUUUU } \\
\text { UU }\end{array}$ \\
\hline $\begin{array}{l}\text { Locomotor } \\
\text { score }\end{array}$ & $\begin{array}{l}000000000000 \\
000000000000 \\
00000000 \\
-----\end{array}$ & $0-000-000-0$ & - & $000-0$ & OUU & UUU & $\begin{array}{l}\text { UUUUUUUUU } \\
\text { UUUUUUUUU } \\
\text { UU }\end{array}$ \\
\hline $\begin{array}{l}\text { Eye/hand } \\
\text { score }\end{array}$ & $\begin{array}{l}\text { O00000000000 } \\
\text { O00000000000 } \\
\text { O0000000 } \\
-----\end{array}$ & $\mathrm{O}-\mathrm{O}-0-00-\mathrm{O}$ & - & $000-0$ & OUU & UUU & $\begin{array}{l}\text { UUUUUUUUU } \\
\text { UUUUUUUUU } \\
\text { UU }\end{array}$ \\
\hline $\begin{array}{l}\text { Performance } \\
\text { score }\end{array}$ & $\begin{array}{l}\text { O०০000000000 } \\
\text { O00000000000 } \\
\text { O०000000 } \\
-----\end{array}$ & $\mathrm{O}-\mathrm{O} 00-000-0$ & - & $000-0$ & OUU & UUU & $\begin{array}{l}\text { UUUUUUUUU } \\
\text { UUUUUUUUU } \\
\text { UU }\end{array}$ \\
\hline
\end{tabular}

Griffiths scores: O score within or above 1 SD of the mean, score below 1 SD of the mean, U untestable, - missing data.

Figure 2 The relation between performance on the Griffiths at 2 years and later performance on the Movement $A B C$ for individual children.

children who were untestable on the WPPSI had also been untestable on the Griffiths.

Statistical analysis

The ability of the Griffiths test to predict performance at age 5-6 was investigated using correlation coefficients and sensitivity and specificity values.

\section{Correlation coefficients}

Pearson correlation coefficients between scores on the Griffiths scales at 1 and 2 years ranged from 0.18 to 0.45 for the five subscales and 0.44 for DQ. Table 3 shows correlations between the Griffiths, Movement ABC, and WPPSI administered at 5-6 years. This includes not only total DQ scores but also scores derived from the three subscales of the Griffiths, which we considered to be make most demands on the perceptual-motor system, the locomotor, eye-hand coordination, and performance scales. The correlations between the Griffiths scores at year 1 and the Movement $\mathrm{ABC}$ were highly significant for all measures but highest for the combined perceptual-motor subscales. In contrast the correlations between the Griffiths and full scale IQ were all negligible. At year 2, the correlations between the Griffiths and the Movement $\mathrm{ABC}$ had diminished but remained statistically significant, whereas the correlations between Griffiths and full scale IQ had increased.

Sensitivity and specificity

Scores on the Griffiths and the WPPSI were dichotomised using a cut off point of one standard deviation (SD) below

\begin{tabular}{|c|c|c|c|c|}
\hline Total $=80$ & $\begin{array}{c}\text { Normal FIQ } \\
n=45\end{array}$ & $\begin{array}{c}\text { Poor FIQ } \\
n=8\end{array}$ & $\begin{array}{l}\text { Missing FIQ } \\
n=2 \\
\text { (non- } \\
\text { cooperation) }\end{array}$ & $\begin{array}{c}\text { Untestable } \\
\text { on WPPSI } \\
n=25\end{array}$ \\
\hline Total DQ & $\begin{array}{l}\text { O00000000000 } \\
\text { O00000000000 } \\
\text { O00000000000 } \\
\text { O०000000- }\end{array}$ & 00000000 & 00 & $\begin{array}{l}\text { UUUUUUUUUUUUU } \\
\text { UUUUUUU९९९०० }\end{array}$ \\
\hline $\begin{array}{l}\text { Personal/ } \\
\text { social } \\
\text { score }\end{array}$ & $\begin{array}{l}000000000000 \\
000000000000 \\
000000000000 \\
00000000-\end{array}$ & 00000000 & 00 & $\begin{array}{l}\text { UUUUUUUUUUUUU } \\
\text { UUUUUUU९९९९० }\end{array}$ \\
\hline $\begin{array}{l}\text { Performance } \\
\text { score }\end{array}$ & $\begin{array}{l}000000000000 \\
000000000000 \\
000000000000 \\
00000000-\end{array}$ & 00000000 & 00 & $\begin{array}{l}\text { UUUUUUUUUUUUU } \\
\text { UUUUUUU } \\
\end{array}$ \\
\hline $\begin{array}{l}\text { Hearing/ } \\
\text { speech } \\
\text { score }\end{array}$ & 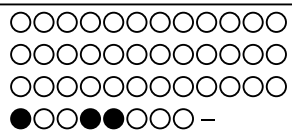 & 00000000 & 00 & $\begin{array}{l}\text { UUUUUUUUUUUUU } \\
\text { UUUUUUU ९०००० }\end{array}$ \\
\hline
\end{tabular}

Griffiths scores: O score within or above 1 SD of the mean, score below 1 SD of the mean,

U untestable, - missing data.

Figure 3 The relation between performance on the Griffiths at 1 year and later performance on the WPPSI for individual children. 


\begin{tabular}{|c|c|c|c|c|}
\hline Total $=80$ & $\begin{array}{l}\text { Normal FIQ } \\
n=45\end{array}$ & $\begin{array}{c}\text { Poor FIQ } \\
n=8\end{array}$ & $\begin{array}{l}\text { Missing FIQ } \\
\quad n=2 \\
\text { (non- } \\
\text { cooperation) }\end{array}$ & $\begin{array}{c}\text { Untestable } \\
\text { on WPPSI } \\
n=25\end{array}$ \\
\hline Total DQ & 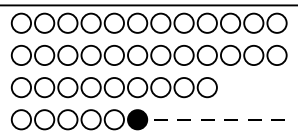 & $-00-0-00$ & $\mathrm{O}-^{-}$ & $\begin{array}{l}\text { UUUUUUUUUUUUU } \\
\text { UUUUUUUUUUUU }\end{array}$ \\
\hline $\begin{array}{l}\text { Hearing/ } \\
\text { speech } \\
\text { score }\end{array}$ & $\begin{array}{l}\text { O00000000000 } \\
\text { O00000000000 } \\
\text { O00000000000 } \\
00------\end{array}$ & $-00-0-00$ & - - & $\begin{array}{l}\text { UUUUUUUUUUUUU } \\
\text { UUUUUUUUUUUU }\end{array}$ \\
\hline $\begin{array}{l}\text { Performance } \\
\text { score }\end{array}$ & 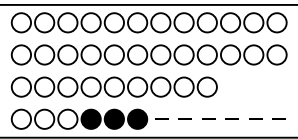 & $-00-O-O O$ & $\mathrm{O}-$ & $\begin{array}{l}\text { UUUUUUUUUUUUU } \\
\text { UUUUUUUUUUUU }\end{array}$ \\
\hline $\begin{array}{l}\text { Personal/ } \\
\text { social } \\
\text { score }\end{array}$ & 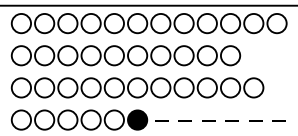 & $-00-0-0$ & $\mathrm{O}-$ & $\begin{array}{l}\text { UUUUUUUUUUUUU } \\
\text { UUUUUUUUUUUU }\end{array}$ \\
\hline
\end{tabular}

Griffiths scores: O score within or above 1 SD of the mean, score below 1 SD of the mean, $\mathrm{U}$ untestable, - missing data.

Figure 4 The relation between performance on the Griffiths at 2 years and later performance on the WPPSI for individual children.

the mean. Scores on the Movement ABC were dichotomised using the 15th centile point. Those children who could not be formally assessed because of the severity of their motor, sensory, and cognitive impairments were assigned to the group performing below the set criteria. Table 4 shows sensitivity and specificity values for the two tests.

Sensitivity and specificity levels are generally considered acceptable when over $85 \%$. On the Movement ABC, sensitivity levels were always below $85 \%$ at both 1 and 2 years but specificity was $100 \%$. Sensitivity levels for scores on the WPPSI were below $85 \%$ at 1 year and above at 2 years, and specificity was well above $85 \%$ at both 1 and 2 years.

\section{DISCUSSION}

Previous studies on the predictive value of developmental tests have mainly focused on the prediction of intellectual outcome. ${ }^{1033} 34$ However, children who fall into "at risk" categories in the neonatal period are not only likely to show cognitive delays, but may also develop difficulties in other aspects of their development, including language and movement. ${ }^{35-39}$ Such difficulties are now known to be associated with educational failure and psychosocial problems.

In the present study, our objective was to determine whether the Griffiths Mental Development Scales might be used to predict neuromotor and perceptual-motor performance at school age as well as cognitive ability in a population of children with neonatal encephalopathy. Since developmental tests used at 1 and 2 years of age, such as the Griffiths and Bayley scales, are largely composed of motor and perceptual-motor items, it seemed possible that they might actually be better predictors of perceptual-motor competence at school age than of cognitive ability.

All existing follow up studies of children with NE report a high proportion of children with severe motor impairment. In this cohort $40 \%(32 / 80)$ had cerebral palsy. Twenty of the 80 children $(25 \%)$ had severe spastic quadriplegia, were untestable at 1 year, and remained so at school age. At 2 years, a further five children with mild quadriplegia or diplegia became untestable and were later unable to complete the Movement ABC. The remaining seven children diagnosed as having cerebral palsy (athetoid, ataxic, or hemiplegic type) managed to perform the tasks contained in the Movement $\mathrm{ABC}$ but obtained poor scores. Of most importance, however, was the fact that 11 children (14\%) without cerebral palsy obtained scores on the Movement ABC at school age, which placed them below the 15th centile. In five cases, the children's perceptual-motor impairment was an isolated problem; in five, additional cognitive impairment was present; and the remaining child was uncooperative but was noted to have extreme difficulty with some of the WPPSI tasks.

Our results on the cognitive assessment were also consistent with those of other studies. For those children who could be formally assessed on the WPPSI, mean IQ was 101 (SD 14). Eight children (15\%) had IQs below 85. Four of these had correspondingly low scores on at least one of the Griffiths subscales by the age of 2 years. Of the remaining four, two spoke English as a second language, which may partly account for their lower than average IQs.

The question of whether the Griffiths scales, administered at 1 or 2 years, might be used to predict performance on the Movement ABC and WPPSI at school age was first addressed by examining correlation coefficients between the early and later tests. Although the year 1 and 2 Griffiths test scores

Table 3 Correlations between scores on the Griffiths scales, the Movement ABC, and the WPPSI

\begin{tabular}{|c|c|c|}
\hline Griffiths scores & $\begin{array}{l}\text { Movement ABC } \\
\text { Total Score† }\end{array}$ & $\begin{array}{l}\text { WPPSI } \\
\text { Full Scale IQ }\end{array}$ \\
\hline 1 year & $\mathrm{n}=55$ & $\mathrm{n}=53$ \\
\hline $\begin{array}{l}\text { Combined locomotor/ } \\
\text { eye-hand/performance }\end{array}$ & $0.72^{* *}$ & 0.19 \\
\hline Personal/social & $0.52^{* *}$ & -0.02 \\
\hline Hearing/speech & $0.54^{* *}$ & 0.11 \\
\hline$D Q$ & $0.71^{* *}$ & 0.14 \\
\hline 2 years & $\mathrm{n}=45$ & $\mathrm{n}=45$ \\
\hline $\begin{array}{l}\text { Combined locomotor/ } \\
\text { eye-hand/performance }\end{array}$ & $0.50^{* *}$ & $0.32^{*}$ \\
\hline Personal/social & $0.35^{\star}$ & $0.36^{*}$ \\
\hline Hearing/speech & $0.36^{*}$ & $0.40^{* *}$ \\
\hline$D Q$ & $0.48^{* *}$ & $0.40^{*}$ \\
\hline
\end{tabular}

Pearson correlation coefficients: ** $p<0.001,{ }^{*} p<0.05$. tOn the Griffiths scales a higher score indicates better performance, while on the Movement $A B C$ a higher score indicates poorer performance. Positive correlations therefore yield a negative coefficient. The negative sign has been omitted in this table. 
Table 4 Sensitivity and specificity of Griffiths scores for predicting outcome on the Movement $A B C$ and the WPPSI

\begin{tabular}{llllll}
\hline Predictor variable & Outcome measure & Sensitivity & Specificity & PPV & NPV \\
\hline 1 year DQ & Movement ABC & $27 / 42(64 \%)$ & $37 / 37(100 \%)$ & $27 / 27(100 \%)$ & $37 / 52(71 \%)$ \\
2 year DQ & Movement ABC & $22 / 33(67 \%)$ & $32 / 32(100 \%)$ & $22 / 22(100 \%)$ & $32 / 43(74 \%)$ \\
1 year DQ & Full Scale IQ & $25 / 33(76 \%)$ & $43 / 44(98 \%)$ & $25 / 26(96 \%)$ & $43 / 51(84 \%)$ \\
2 year DQ & Full Scale IQ & $27 / 30(90 \%)$ & $38 / 39(97 \%)$ & $27 / 28(96 \%)$ & $38 / 41(93 \%)$ \\
\hline
\end{tabular}

PPV, positive predictive value; NPV, negative predictive value.

were only moderately correlated with each other, all of the subscales were more highly correlated with Movement ABC scores than with the WPPSI scores, regardless of their label. Even though the highest correlation we obtained was highly significant (0.72), this accounts for less than $50 \%$ of the variance in the children's scores at school age and is therefore of little practical significance. The correlation between the Griffiths scores and IQ scores was slightly higher at 2 years than at 1 year, but in this case the highest correlation accounted for even less of the variance, only $20 \%$.

It has been argued that for clinicians, a more appropriate method of studying prediction is to abandon the use of continuous measures and employ a more simplified category system based on the concept of risk. ${ }^{670}$ Although cut-off points vary from study to study, the most commonly used procedure is to dichotomise the sample using either one standard deviation below the mean as the divisor or a selected centile point at the lower end of the distribution. We did this and calculated sensitivity and specificity values for the Griffiths scales in relation to the Movement $\mathrm{ABC}$ and WPPSI.

For the Movement ABC, sensitivity at both 1 and 2 years was relatively low (64\% and 67\% respectively) while specificity values were $100 \%$ in both cases. This suggests that a normal score on the Griffiths scales at 1 and/or 2 years does not always predict a normal Movement ABC score. In contrast, an abnormal score on the Griffiths is very likely to be associated with poor performance at school age.

In order to determine whether there was anything special about the children with poor school age performance who had normal results on early assessments, we examined the data for each child individually. What emerged here was that nearly all of the children diagnosed as having hemiplegia "passed" the Griffiths test. Of the five children who scored poorly on the Movement $\mathrm{ABC}$, only one had a poor score on one of the subscales of the Griffiths scales. In the children without cerebral palsy who had poor scores on the Movement $\mathrm{ABC}$, the Griffiths scores tended to be normal at 1 year $(80 \%)$ but not at 2 years, when abnormal scores on at least one subscale were found in $63 \%$ of the children.

In sum, our results suggest that although early neurodevelopmental assessment can to some extent predict outcome at school age, a normal neurodevelopmental assessment at 1 and 2 years does not exclude cognitive, neurological, or perceptual motor abnormalities at school age. Since the sensitivity values for the Griffiths test were slightly higher at 2 years than at 1 , one might be tempted to conclude that a neurodevelopmental examination at 2 years might identify children with abnormal outcome at school age better than the examination performed at 1 year. However, the differences in the sensitivity values were relatively small and we could not exclude the possibility that professional intervention might have influenced outcome. Many children with evidence of abnormal development see physiotherapists, occupational therapists, and/or speech therapists and often receive systematic training in test related activities. Since the children in our study were followed up in various local centres and did not receive a uniform programme of rehabilitation, it was impossible to examine this issue further.

The relatively high incidence of false negatives found in this study raises the question of whether children with normal neurodevelopmental tests at 1 and even 2 years should be discharged, as often happens in order to make the most effective use of limited resources. In our cohort, seven of 37 (19\%) children who had normal results on all subscales on the Griffiths had an abnormal motor outcome at school age. Four of these seven however had hemiplegia, which we suggest reveals a weakness in the Griffiths scales. Since the scales do not provide a measure of performance for each side of the body separately or the quality of unimanual performance, any asymmetry remains unrecorded. In these cases, a more detailed assessment of unilateral performance or a neurological examination might have helped to identify asymmetry of hand function and reduce the number of false negatives. The remaining three children, however, were not identifiable at all in the early years. Children with movement difficulties, with or without a clear diagnostic label, may have serious problems at school. This is not only because motor skills are required to access the increasingly practical school curriculum but also because poor motor skills are often associated with poor attention, low self esteem, and anxiety. ${ }^{41-44}$ Our failure to identify such children in infancy means that they miss out on early intervention programmes which may help them to cope better at home and at school.

\section{Authors' affiliations}

A L Barnett, F Cowan, L Dubowitz, Department of Paediatrics, Imperial College School of Medicine, Hammersmith Campus, London, UK E Mercuri, Department of Child Neurology, Catholic University, Rome, Italy

A Guzzetta, Department of Child Neurology and Psychiatry, Stella Maris Institute, University of Pisa, Italy

S E Henderson, School of Psychology and Human Development, Institute of Education, University of London, UK

L Haataja, Department of Paediatrics and Child Neurology, Turku University Central Hospital, Turky, Finland

This study was supported by grants from Action Research and SCOPE

\section{REFERENCES}

1 Bayley N. California Infant Scale of Mental Development. Berkeley: University of California Press, 1936.

2 Gesell A. Thompson H. Infant behaviour: its genesis and growth. New York: McGraw-Hill, 1934.

3 Cattell P. The measurement of intelligence of infants and young children. New York: The Psychological Corporation, 1940.

4 Griffiths R. The abilities of babies. High Wycombe, UK: The Test Agency, 1954.

5 Griffiths R. The abilities of young children. High Wycombe, UK: The Test Agency, 1970.

6 Illingworth RS. The normal child. Some problems of the early years and their treatment. Edinburgh: Churchill Livingstone, 1991.

7 Largo RH, Graf S, Kundu S, et al. Predicting developmental outcome at school age from infant tests of normal, at-risk and retarded infants. Dev Med Child Neurol 1990;32:30-45.

8 Spreen O, Risser AH, Edgell D. Developmental neuropsychology. New York: Oxford University Press, 1995. 
9 Hindley CB. Stability and change in abilities up to five years: group trends. J Child Psychol Psychiatry 1965;6:85-99.

10 Werner $\mathbf{E}$, Honzik M, Smith R. Prediction of intelligence and achievement at 10 years from 20 month paediatric and psychological examinations. Child Dev 1968:39:1063.

11 Goffeney B, Henderson NB, Butler BV. Negro-white, male-female eight-month developmental scores compared with seven-year WISC and Bender test scores. Child Dev 1971;42:595-604.

12 McCall RB, Appelbaum MI, Hogarty PS. Developmental changes in mental performance. Monographs of the Society for Research in Child Development 1973;38:1-84

13 Hunt JV. Developmental risk in infants. In: Keogh BK, ed. Advances in special education. Connecticut: JAI Press, 1986:25-61.

14 McCall RB. Environmental effects on intelligence: the forgotten realm of discontinuous non-shared within-family factors. Child Dev 1983;54:408-15

15 Illingworth RS. The development of the infant and young childNormal and abnormal, 9th edn. London: Churchill Livingstone, 1987.

16 Kitchen W, Ford G, Rickards A, et al. Children of birth weight < $1000 \mathrm{~g}$ : changing outcome between ages 2 and 5 years. J Pediatr 1987;110:283-8.

17 Bowen JR, Gibson FL, Leslie Gl, et al. Predictive value of the Griffiths assessment in extremely low birthweight infants. J Paediatr Child Health 1996;32:25-30

18 Van den Hout B, Eken P, Van der Linden D, et al. Visual, cognitive, and neurodevelopmental outcome at $5 \frac{1}{2}$ years in children with perinatal haemorrhagic-ischaemic brain lesions. Dev Med Child Neurol 1998;40:820-8.

19 Losse A, Henderson SE, Elliman D, et al. Clumsiness in children-do they grow out of it? A 10-year follow-up study. Dev Med Child Neurol 1991;33:55-68.

20 Gillberg C, Rasmussen P, Carlstrom G, et al. Perceptual, motor and attentional deficits in six-year-old children. Epidemiological aspects. J Child Psychol Psychiatry 1982;23:131-44.

21 Gillberg C. Perceptual, motor and attentional deficits in Swedish primary school children. Some child psychiatric aspects. J Child Psychol Psychiatry 1983;24:377-403.

22 Hellgren L, Gillberg C, Gillberg IC, et al. Children with deficits in attention, motor control and perception (DAMP) almost grown up. General health at 16 years. Dev Med Child Neurol 1993;35:881-92.

23 Hellgren L, Gillberg IC, Bagenholm A, et al. Children with deficits in attention, motor control and perception (DAMP) almost grown up: psychiatric and personality disorders at age 16 years. J Child Psychol Psychiatry 1994:35:1255-71.

24 Hadders-Algra M, Huisjes HJ, Touwen BCL. Perinatal risk factors and minor neurological dysfunction: significance for behaviour and school achievement at nine years. Dev Med Child Neurol 1988;30:482-91.

25 Barnett A, Mercuri E, Rutherford M, et al. Neurological and perceptual-motor outcome at 5-6 years of age in children with neonatal encephalopathy: relationship with neonatal brain MRI. Neuropediatrics 2002;33:242-8.
26 Griffiths R. The abilities of young children. High Wycombe, UK: The Test Agency, 1976.

27 Touwen BCL. Examination of the child with minor neurological dysfunction, 2nd edn. London: SIMP, 1971.

28 Kakebeeke TH, Jongmans MJ, Dubowitz LMS, et al. Some aspects of the reliability of Touwen's Examination of the child with minor neurological dysfunction. Dev Med Child Neurol 1993;35:1197-205.

29 Hagberg B, Hagberg G, Olow I. The changing panorama of cerebral palsy in Sweden 1954-70. I. Analysis of general changes. Acta Paediatr 1975:64:187-92.

30 Henderson SE, Sugden DA. Movement assessment battery for children. Kent: The Psychological Corporation, 1992

31 Croce RV, Horvat M, McCarthy E. Reliability and concurrent validity of the Movement Assessment Battery for Children. Perceptual and Motor Skills $2001 ; 93: 275-80$

32 Weschler D. Wechsler Pre-school and Primary Scale of Intelligence-Revised Kent: The Psychological Corporation, 1990.

33 Escalona SK, Moriarty A. Prediction of school-age intelligence from infan tests. Child Dev 2002:32:597-605.

34 McCall RB, Hogarty PS, Hurlburt N. Transitions in infant sensorimotor development and the prediction of childhood IQ. American Psychologist 1972;27:728-48.

35 Robertson C, Finer N. Term infants with hypoxic-ischemic encephalopathy: outcome at 3.5 years. Dev Med Child Neurol 1985;27:473-84.

36 Robertson CM, Finer NN. Long-term follow-up of term neonates with perinatal asphyxia. Clin Perinatol 1993;20:483-500.

37 Robertson CM, Finer NN, Grace MG. School performance of survivors of neonatal encephalopathy associated with birth asphyxia at term. J Pediatr $1989 ; 114: 753-60$

38 Robertson CM, Finer NN, Grace MG. School performance of survivors of neonatal encephalopathy associated with birth asphyxia at term. J Pediatr 1989;114:753-60.

39 Rands CE, Rose AS, Marlow N, et al. Cognitive impairment in 6-8 year old children following neonatal encephalopathy [abstract]. Arch Dis Child 2001;84:A16-17

40 McCall RB. Predicting developmental outcome. Resume and redirection. In: Brazelton TB, Lester BM, eds. New approaches to developmental screening of infants. New York: Elsevier, 1983:13-26.

41 Goodman R. Psychological aspects of hemiplegia. Arch Dis Child 1997;76:177-8

42 Frampton I, Yude C, Goodman R. The prevalence and correlates of specific learning difficulties in a representative sample of children with hemiplegia. Br J Educ Psychol 1998;68:39-51.

43 Schoemaker MM, Kalverboer AF. Social and affective problems of children who are clumsy: how early do they begin? Adapted Physical Activity Quarterly 1994;11:130-40.

44 Skinner RA, Piek JP. Psychosocial implications of poor motor coordination in children and adolescents. Human Movement Science 2001;20:73-94.

\section{IMAGES IN PAEDIATRICS}

\section{Confusing coarctation}

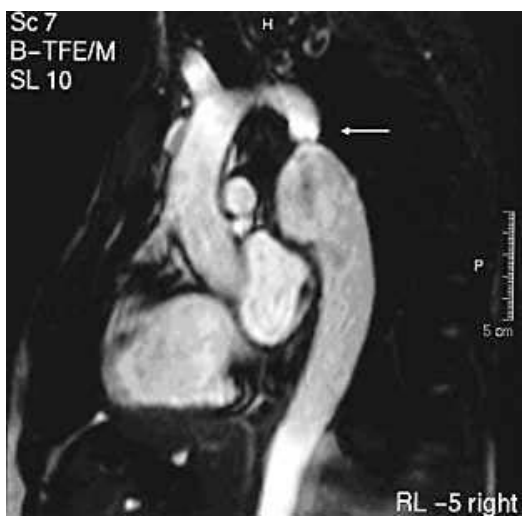

$T$ his 15 year old boy presented with purpuric spots on his lower limbs, ankle pain, and swelling. On examination he was found to have hypertension, and although HenochSchönlein purpura was felt to be the more likely diagnosis, the absence of femoral pulses was perplexing. For this reason we considered an infected coarctation which would explain all the presenting features. Investigations revealed microcytic anaemia, raised $\mathrm{C}$ reactive protein, haematuria, and Streptococcus viridans on blood culture. Echocardiography confirmed the coarctation and magnetic resonance imaging the infected proximal aneurysm, which was later successfully resected.
J Bentham, P Todd, P Evans Arrowe Park Hospital, Upton, Wirral, UK; suz-jim@fish.co.uk 